\title{
A LIFE AND EFFICIENCY TEST OF INCANDESCENT LAMPS.
}

BY PROFESSOR B. F. THOMAS AND MESSRS. P. MARTIN AND R. H. HASSLER.

Much has been written and said concerning the efficiency of the incandescent lamp, and of the relation between its efficiency and the length of life to be expected from it. High efficiency lamps have their advocates and low efficiency lamps have theirs. It is pretty well understood by those whose work has put them in a position to appreciate the facts, that the question as to the choice of the lamps which will have the best influence on the profit and loss account of the consumer, depends on other things than first cost, efficiency and life. It is understood by such persons that the cost of producing the current supplying the lamps, and the steadiness of voltage maintained on the lines are important factors in the choice; the high efficiency, short life lamp being best under conditions of steady voltage and expensive current, and the low efficiency, long life lamp where current is cheap or regulation poor.

The general public, however, does not understand the question so clearly, and unfortunately that part of the literature of the subject which is found in the advertising columns of the electrical press, does not tend to relieve the embarrassing ignorance of the buyer. Statements of the marvelously long life of certain lamps are followed in a week by ludicrous accounts of searches for them with a lantern, and of the imminent peril of the country, arising from the exhaustion of our coal supply by the running of such lamps. Again we are startled by statements of the wonderful results attained by lamps of some certain make, as indicated by the number of such lamps which can be maintained at full brilli- 
ancy by the expenditure of a horse power. But immediately it is said that the insane asylums of the country are full of station managers and stockholders, whose cases have become hopeless through contemplation of the number of such lamps bought during the year. There is as great divergence between the published claims of lamp makers, and the statements of the experience of station managers. Makers generally say that they will guarantee 600 hours life for their lamps, and from 10 to 14 or more lamps per horse power, but some station managers insist that they do not get an average of 400 hours life.

Lamp makers have, from necessity, made a study of their own Jamps, and of those of other makers also, as to efficiency and life, and they know, better than any one else, the character of the incandescent lamp of to day. But naturally they, if they say anything on the subject, tell about the good points of their own goods, and the bad points of others, and, as naturally, the buying public say that all their statements are questiunable. Much good work has been, and is being done in college laboratories on lamp efficiencies, and the results are published and accepted, but on the equally important question of life the laboratories are silent. The tests of the Franklin Institute stand as a model piece of work, but that work is now eight years old. Farther, the lamps tested at that time were furnished by the makers themselves for the purpose of test. Believing that the public would be interested in the results of a test of commercial lamps, as to both efticiency and life, the writers have carried out such a test and give the results in this japer. The test was made at the Electrical Laboratory of the Ohio State University, Columbus, O., and all expenses incurred were paid by the trustees.

Considering it of prime importance for our object that the lamps tested should be of the same character as those usually sold to consumers, we bought some lamps of regular dealers, as in the usual course of business, and obtained othere from lots supplied for central station use. Lamps of the following makes were obtained, no attempt being made to get lamps of any given efficiency of any make: A. B. C., Beacon, Columbia, Economic, Packard, Pennsylvania, Standard, Thomson-Houston, Edison, Perkins, Sawyer-Man, and Steuben. In ordering (through persons purchasing for us in Chicago and New York) we called for ten 110. volt lamps of $16 \mathrm{c}$. P. in each case, but on receiving the lamps we found three lamps out of 10 of one make labeled 111 volts. The 
three were excluded and seven put in; but another lot of 10 of the same make, correctly labeled, was obtained. 'Ten of another make were received with the original marking, 111 volts in ink, changed by pencil to 110 volts. They were also excluded, and a new lot of 10 of that make, correctly labeled, obtained. Ten Sunbeam lamps were divided into two lots of five each, evidently supplied as a sample lot, and were excluded. We conld not get others of that make in time to enter the test. There were, therefore, in all 127 lamps, labeled 110 volts and 16 c. P., of 12 well known makes, 17 lamps in two separate lots of one make, and 10 each of 11 different makes.

For convenvience in making the photometric measurements, the lamps were mounted vertically in horizontal rows of 20 on a light vertical rack, six feet high and 20 feet long. The rack was made in the form of ordinary shelving, having five vertical pieces of pine, four inches wide and one inch thick, and four horizontal strips of the same width, the four inch face being horizontal. The whole was rigidly braced diagonally, suspended by strong cords passing over pulleys in the ceiling and counterpoised by weights. This arrangement enabled us to bring each row of lamps to the level of the photometer described below, by raising or lowering the rack, and definiteness of position was secured by spiking to the brick wall of the photometer room two 2 by 4 inch vertical guides, against which the rack was pressed, and fastened each time by stout inclined pins. passed through the diagonal braces into holes bored in the guides.

A system of positive mains was arranged by fastening a No. 2 wire along the face of each horizontal strip in the rack, and joining them at the middle of the rack by a vertical No. 0 wire. A set of negative mains similarly made was placed on the opposite side of the rack. Flexible okonite cable of equivalent section joined the No. 0 vertical wires to the ends of the dynamo mains, fastened to the wall, which point is called the centre of distribntion. Porcelain keyless wall sockets were screwed in place on the horizontal rack strips, and joined to the mains on each side by No. 16 wire. All connections were well soldered.

A Thomson centiampere balance provided also with a resistance for obtaining standard potential readings was used as a standard for current and potential. Its constants had been repeatedly checked by a voltmeter, and by Clark cells, and found correct and constant to within one part in one thousand. Two Weston 
milliampere meters and two Weston voltmeters were used in the current and potential readings on the lamps. The ammeters were graduated to 10 milliamperes, readable to one milliampere, and the voltmeters in volts, readable to tenths. The Weston instruments were compared with the Thomson balance at intervals, and found correct, or affected by a small, constant error, which was applied as a correction.

Current was supplied to the lamps by a 200-light ThomsonHouston dynamo, of the spherical armature type, which proved to be an excellent machine for the purpose. Owing to the variable speed of the engine, due to varying load and steam pressure, a special automatic regulator was devised and applied to the dynamo, to keep the potential at the centre of distribution constant. This was effected by causing a small motor to slide a contact piece along two vertical german silver wires joined to an extension of the field coil of the dynamo, a current being sent through the motor in one direction or the other as needed, by relay points, the relays being controlled by an indicator attached to wires leading to the centre of distribution. As used, the combination proved very satisfactory, keeping the potential difference at the centre at 110 volts, within a limit of $\frac{\varepsilon}{4}$ of a volt either way. It could readily have been set to a smaller margin, but that was not considered necessary.

For the candle power measurements a two candle power Methven screen was used, the gas being passed through a Methven carbureter containing pentane. Its constant was checked by standard candles. Three 32-candle power Edison lamps were used as working standards. Each. was checked at intervals by comparison with the Methven screen on a 100-inch photometer bar, a slide wire resistance enabling us to adjust the current through the lamp to a definite strength, which was always the same for a given lamp. The currents used were such as to develop about 18 candle power in the standard lamp. Instead of the usual Bunsen or Leeson disk, we used a Lummer-Brodhun prism, made by Schmidt and Haensch. It gave us much better satisfaction than the best Leeson disks we have been able to obtain.

In front of the test rack and parallel with it was placed a bench with a guiding rail, along which a Weber portable photometer was arranged to slide, so as to be placed successively in front of each lamp in a row on the test rack. Instead of the little benzine standard lamp which was removed, a 16-candle incandescent 
called the reference lamp was placed at a distance of about 800 centimeters from the end of the tube to which the bezine standard is attached. In taking the candle power of the lamps under test, the photometer was first placed in front of one of the working standards. By means of a conveniently arranged slide wire resistance, the current through the standard lamp was accurately adjusted to the strength used with it, when its candle power was measured on the standard photometer against the Methven screen. Care was taken that the adjustment of current was right when the measured potential at the terminals of the reference lamp was just 110 volts. Readings of the standard lamp against the reference lamp being taken the photometer was then moved in frout of each lamp under test, and readings taken of each against the reference lamp. The candle power of each lamp was then found by comparing these readings with those obtained opposite the standard lamp. The reference lamp being of the same character as those under test, and connected to the same mains, the slight changes in potential allowed by the regulator affected alike the candle power of the reference lamp and the test lamp being read, allowing us to take readings more rapidly than we could have done had it been necessary to adjust and hold the potential at 110 volts.

Before the duration test began, the mean horizontal candle power of each lamp was determined in the usual way, and the ratio of this mean to the candle power found when the plane of the ends of the filament was perpendicular to the photometer bar was found, and used as the distribution factor. The lamps were placed on the rack in the same position with respect to the Weber photometer, at a distance of about one meter from its plate, the exact distance of each lamp being measured and used in the calculations on it. All results are expressed in terms of mean horizontal candle power. The unavoidable delays encountered in starting the test made it impossible to determine the spherical distribution without cutting short the time of run which we had set as desirable, viz., 1,200 hours. The duration test was begun on March 17, and it was necessary to run night and day, Sundays excepted, until the night of May 14, to complete the 1,200 hours. The run began with 77 lamps on the rack. The remaining 50 lamps were received later, and placed on the rack with the others 187 hours after the start.

As the methods used involve nothing particularly new, and have been fully described in print many times, we have consid 
ered it unnecessary to do more than state the general outlines, as above.

The object we had in view in undertaking the test was, to determine the character of the incandescent lamp as a commercial product, not as a scientific instrument. The number of lamps of each make taken was, of course, too small to base a fair judgment on as to the absolute or relative merit of the lamps generally sold by the makers. For that purpose some hundreds of lamps of each make, taken from different lots, would have to be tested, which it was of course impossible for us to do. For this reason we have considered it unfair to the several makers concerned, to give their names in connection with the results on their lamps, but have instead designated each make by a letter, and each lamp by a number. We believe, however, that the average of the results of all makes may be taken to represent fairly well the character of the average commercial lamp.

The results of the test are given in the following tables, the values given being in each case the average for a given make of lamp. Table I. gives in the second column the average value of the distri. bution factors found for the 10 lamps of make "A," and the average value of the mean horizontal candle powers for those lamps at intervals after the beginning of the duration test, expressed in hours by numbers in the first column. The third column gives corresponding values for the lamps of make "B," and so on. Table I. includes the lamps started March 17. Table II. contains similar data for the lamps started 187 hours later.

\section{Table I.}

\begin{tabular}{|c|c|c|c|c|c|c|c|c|}
\hline Lamp. & A & $B$ & $\mathrm{C}$ & $\mathrm{D}$ & $\mathrm{E}$ & F & $\mathrm{G}$ & $\mathrm{K}$ \\
\hline $\begin{array}{l}\text { Distribution } \\
\text { factor }\end{array}$ & 1.05 & 1.07 & r.or & I. I I & .989 & I.OI & I.OI & 1.02 \\
\hline $\begin{array}{c}\text { Hours from } \\
\text { stait }\end{array}$ & C. $P$. & C. P. & C. P. & C. P. & C. P. & C. P. & C. P. & C. $\mathbf{P}$ \\
\hline 0 & 16.0 & $x_{3} \cdot I$ & $\mathrm{r}_{4 .} \mathrm{I}$ & 16.1 & $\mathrm{r}_{5} .9$ & 14.2 & I7 I & 17.0 \\
\hline 93 & 15.0 & 12.4 & I 48 & I6.I & r.7 & 12.1 & 15.9 & 16.1 \\
\hline 233 & 13.65 & 12.4 & 14.9 & 16.0 & 13.1 & 12.9 & 16.4 & 16.5 \\
\hline 324 & 12.2 & 11.0 & 14.8 & 13.9 & I0.9 & 20.8 & 14.5 & I3.9 \\
\hline 392 & II.7 & 10.5 & 14.0 & 13.2 & I0. 5 & 10.4 & 13.6 & I 3.4 \\
\hline $44 I$ & II. 3 & 10.2 & 14.2 & 12.7 & 10. $\mathrm{I}$ & 10.2 & $13 \cdot 3$ & $r_{3} \mathrm{I}$ \\
\hline 537 & 10.9 & 9.9 & 13.6 & $12 \cdot 3$ & $9 \cdot 9$ & 10.0 & 13.0 & 13.0 \\
\hline 637 & 10.7 & IO. I & 13.0 & II. 9 & 95 & I0. 1 & 124 & 12.4 \\
\hline 785 & 94 & 9.2 & 12.6 & 10.5 & $9 . \mathrm{I}$ & g.I & II. 4 & 10.0 \\
\hline 833 & $9 \cdot \pi$ & 8.6 & All out & IO.I & 8.5 & 8.5 & 10.9 & 10.3 \\
\hline 883 & 8.6 & 8.2 & $\cdots$ & $9 \cdot 3$ & 7.7 & 8.0 & ro. 4 & 9.8 \\
\hline 972 & 8.6 & $8 \cdot 3$ & $\ldots$ & 9.2 & 7.6 & 8.0 & 10.4 & 10.0 \\
\hline $\mathrm{I}, \mathrm{IO} 5$ & 8.6 & 8.2 & $\cdots$ & 9.2 & $7 \cdot 4$ & 8.0 & 10.3 & 9.5 \\
\hline$I, 190$ & 8.2 & 8.0 & $\cdots$ & 9.0 & $7 \cdot 5$ & 8.0 & 10.4 & 9.6 \\
\hline
\end{tabular}


TAble II.

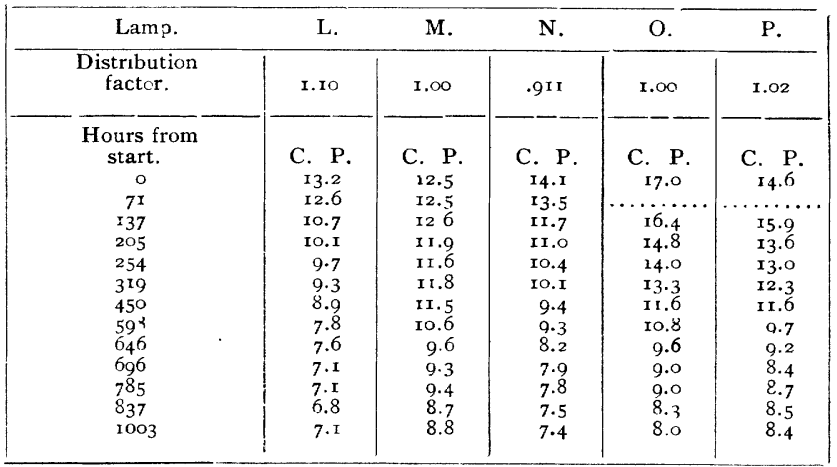

Table III. gives the average current strength found for each make of lamp, at times given in the first column:

\section{Table III.}

\begin{tabular}{|c|c|c|c|c|c|c|c|c|c|c|c|c|c|}
\hline \multirow{2}{*}{ Lamp. } & \multicolumn{13}{|c|}{ Mean current strength in amperes. } \\
\hline & A & $\mathrm{B}$ & $\mathrm{C}$ & $\mathrm{D}$ & $\mathrm{E}$ & F & G & $\mathrm{K}$ & $\mathrm{L}$ & M & $\mathrm{N}$ & 0 & $\mathbf{P}$ \\
\hline Hours. & & & & & & & - & - & - & - & - & - & - \\
\hline $\begin{array}{c}110015 . \\
0\end{array}$ & $.56-$ & .532 & .693 & .639 & .589 & $.53^{2}$ & .662 & $.6 \mathrm{I}_{3}$ & $.4 \div 8$ & .547 & .568 & .609 & .536 \\
\hline 100 & $\cdots$ & & & & & & & & .444 & $.53^{2}$ & .557 & .665 & .534 \\
\hline 107 & .57 .5 & .545 & .760 & .668 & $.58 \mathrm{r}$ & .519 & $.68 \mathrm{c}$ & .6 .9 & $\cdots$ & $\cdots$ & $\cdots$ & & \\
\hline $\begin{array}{l}275 \\
380\end{array}$ & $.5^{67}$ & .540 & $\begin{array}{ll}.77^{8} \\
\ldots\end{array}$ & $\begin{array}{c}. C_{55} \\
\ldots\end{array}$ & .566 & $\begin{array}{c}5^{1} \\
\ldots \ldots\end{array}$ & {$\left[\begin{array}{c}681 \\
\ldots \ldots\end{array}\right.$} & $\begin{array}{l}\cdots \\
\cdots \\
\end{array}$ & .423 & $\ldots \ldots$ & $\begin{array}{l}\ldots \\
.528\end{array}$ & .615 & $.51 \mathrm{I}$ \\
\hline 555 & .548 & 540 & .770 & .633 & $.54 \mathbf{r}$ & .504 & .562 & $\ldots$ & $\ldots$ & $\ldots$ & $\ldots$ & $\ldots$ & $\left|\begin{array}{ll}n \\
3 \cdot i\end{array}\right|$ \\
\hline $6 \mathrm{I}_{5}$ & & & & & & & & & .418 & .505 & .519 & .505 & $.49 \mathrm{~s}$ \\
\hline 790 & .540 & .535 & .770 & .619 & $.5 \vdots 0$ & .498 & .654 & $.5^{8 \mathrm{I}}$ & & & & & \\
\hline $93^{\circ}$ & & & & & $\cdots$ & $\ldots$ & & $\ldots$ & .417 & .500 & .508 & $.5^{8} 5$ & .476 \\
\hline $\mathrm{I}, \mathrm{IO} 5$ & $.53=$ & .529 & .000 & $.6 \mathrm{Ir}$ & $.5^{17}$ & .495 & .649 & .577 & $\ldots$ & $\ldots$. & $\ldots$ & $\ldots$ & $\ldots$ \\
\hline
\end{tabular}

Table IV. gives the mean percentage of original candle-power for each make at times given in the first column:

TABLE IV.

\begin{tabular}{|c|c|c|c|c|c|c|c|c|c|c|c|c|c|c|}
\hline Lamp. & A & B & C & $\mathrm{D}$ & $\mathrm{E}$ & $\mathrm{F}$ & G & $\mathrm{K}$ & $\mathrm{L}$ & M & $\mathrm{N}$ & $O$ & $\mathrm{P}$ & 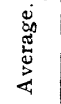 \\
\hline Hours. & $\%$ & $\%$ & $\%$ & $\%$ & $\%$ & $\%$ & $\%$ & $\%$ & $\%$ & $\%$ & $\%$ & $\%$ & $\not$ & $\%$ \\
\hline & 100 & 100 & 100 & 100 & 100 & 100 & roo & 100 & roo & 100 & 100 & 100 & 100 & ICO \\
\hline 100 & 93 & 94 & 106 & IOI & 92 & 93 & 95 & 93 & 87 & 100 & 87 & 95 & 107 & 95.6 \\
\hline 200 & 86 & 80 & 109 & 99 & 84 & 86 & 90 & 87 & 78 & 98 & 79 & 87 & 97 & 90 \\
\hline 300 & 79 & 83 & 106 & 93 & 77 & $8 \mathbf{I}$ & 86 & 83 & 72 & 94 & 72 & 80 & 86 & 84 \\
\hline 400 & 74 & 80 & 102 & 82 & 7 & .7 & $8 r$ & 78 & 67 & $9^{(1)}$ & 67 & 72 & 78 & 78.4 \\
\hline 500 & kg & 73 & 98 & 75 & 66 & 70 & 77 & 74 & 63 & 86 & 63 & 66 & 71 & 73 \\
\hline 6 & 64 & & 94 & 70 & $6 \mathbf{r}$ & 66 & 73 & $7 i$ & 59 & 80 & $6 c$ & 60 & 65 & 68.6 \\
\hline 700 & $6 \mathrm{r}$ & 67 & $9^{I}$ & 66 & 57 & 62 & 70 & 67 & 55 & 75 & 56 & 55 & 60 & 64.7 \\
\hline 8 & $5^{8}$ & 64 & 90 & $6_{3}$ & 53 & 59 & 66 & $\sigma_{3}$ & 34 & 73 & 55 & 51 & 58 & 62 \\
\hline 900 & 55 & $\sigma_{3}$ & All out & 60 & $5 \mathrm{I}$ & 57 & $\sigma_{3}$ & 59 & $5^{2}$ & 70 & 53 & 49 & 56 & $57 \cdot 4$ \\
\hline $\mathrm{I}, \mathrm{OOO}$ & 54 & 62 & $\ldots \ldots, \ldots$ & $5^{8}$ & 49 & $5^{\circ}$ & 62 & 58 & 54 & $7 \circ$ & 52 & 47 & 57 & 56.6 \\
\hline$\infty$ & $5^{2}$ & $6 I$ & $\ldots \ldots \ldots$ & 57 & 47 & 56 & $6 \mathrm{I}$ & 57 & & & $\ldots$. & & & 55.8 \\
\hline $\mathrm{I}, 200$ & 51 & $6 \mathbf{I}$ & 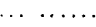 & $5^{6}$ & 47 & 56 & $6 \mathrm{I}$ & 57 & $\ldots$ & $\ldots$ & $\ldots$ & $\ldots$ & $\ldots$ & 55.4 \\
\hline
\end{tabular}


Table V. gives the average watts per mean horizontal candle power for each make, at times given in the first column :

Table V.

\begin{tabular}{|c|c|c|c|c|c|c|c|c|c|c|c|c|c|c|}
\hline & \multicolumn{14}{|c|}{ Watts per mean horizontal candle power. } \\
\hline & A & B & $\mathrm{C}$ & $\mathrm{D}$ & $\mathrm{E}$ & F & $\mathrm{G}$ & $\mathrm{K}$ & $\mathbf{L}$ & M & $\mathrm{N}$ & 0 & $\mathrm{P}$ & Av. \\
\hline $\mathrm{Ho}$ & & & & & - & & & -- & & - & - & 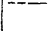 & - & - \\
\hline & 3.0 & $4 \cdot 4$ & $5 \cdot 4$ & $4 \cdot 3$ & 4.1 & $4 \cdot 1$ & 4.2 & 3.9 & 3.8 & 4.8 & $4 \cdot 4$ & 3.9 & 4.0 & 4.2 \\
\hline IC & 43 & 4.8 & 5.0 & 4.5 & $4 \cdot 4$ & $4 \cdot 3$ & 4.6 & $4 \cdot 3$ & 4.2 & $4 \cdot 7$ & 49 & 4.5 & 3.8 & $4 \cdot 5$ \\
\hline & 4. & 5.1 & 5.6 & 4.5 & 4.7 & 4.6 & 4.9 & 4.6 & 4.6 & 4.7 & $5 \cdot 3$ & 4.9 & 4.1 & 4.8 \\
\hline & 4.9 & 5.4 & 5.7 & 4.8 & 5.0 & 4.9 & 5.0 & 4.8 & 4.9 & 4.8 & 5.7 & 5.2 & $4 \cdot 5$ & 5.0 \\
\hline & 5.2 & 5.6 & 5.0 & $5 \cdot 3$ & 5.4 & $5 . \mathrm{T}$ & $5 \cdot 3$ & 5.0 & 5.2 & 4.9 & $6 . \mathrm{I}$ & 5.4 & 4.9 & $5 \cdot 3$ \\
\hline & $5 \cdot 5$ & 6.1 & 6.2 & 5.8 & 5.7 & 5.5 & $5 \cdot 5$ & 5.2 & 5. & 5.5 & $6 \cdot 3$ & 5.8 & 5.2 & 5.0 \\
\hline 60 & 5.8 & 6.4 & 5.4 & 6.1 & 6.1 & 5.8 & 5.7 & 5.4 & 5.8 & 55 & 6.7 & 6.3 & $5 \cdot "$ & 5.9 \\
\hline & $6 . x$ & 6.7 & 6.6 & 64 & 6.5 & 6.1 & 6.0 & 5.6 & 6.1 & 5. & 7.0 & 6.9 & 6.I & 6.3 \\
\hline & 6.4 & 6.9 & 6.7 & 6.7 & 7.0 & 6.4 & 6.3 & 5.9 & $6 \cdot 3$ & 5.9 & 72 & 7.4 & 6.2 & 6.6 \\
\hline & 6.7 & $7 \mathrm{I}$ & $\ldots$ & 7.0 & 7.2 & 6.6 & 6.6 & 6.2 & 6.4 & 0.5 & $7 \cdot 4$ & 7.7 & 6.3 & 6.8 \\
\hline 1,000 & 6.8 & 7.1 & $\ldots$ & 7.2 & 7.4 & 6.8 & 6.7 & 6.4 & 6.2 & 6.1 & 7.5 & 7.9 & 6.2 & 6.8 \\
\hline & 7.0 & 7.2 & & 73 & 7.5 & 6.7 & 6.8 & 0.5 & & . & & $\ldots$ & $\ldots$ & 7.0 \\
\hline 1,200 & $7 \cdot 1$ & 7.2 & & 7.4 & 7.6 & 6.7 & 6.7 & 6.5 & & & & & & \\
\hline
\end{tabular}

From the data given in the tables plates I. to XIII. are constructed. Each plate refers to a single make of lamp. Plate I. gives curves relating to the average lamp of make $A$. In it curve $a$ gives percentage of initial candle power, $b$ gives watts per candle power, $c$ gives candle power, $d$ gives current strength, and $e$ gives number of lamps burning. The time scale is common to all curves. The curves are lettered alike, are drawn to the same scale, and have the same starting points in each of the plates.

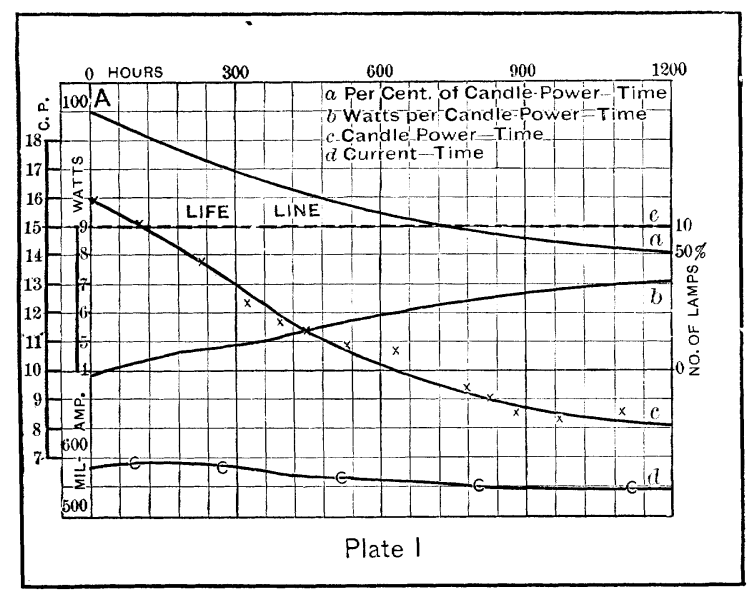

The make of lamp referred to is indicated by the letter in the upper left hand corner of each plate. Curves $c, d$ and $e$ are plotted from observed values, but curves $a$ and $b$ are obtained 
from points 100 hours apart on $c$ and $d$, combined, with the volt. age 110 for $b$.

Want of time, due to the pressure of other duties, prevented

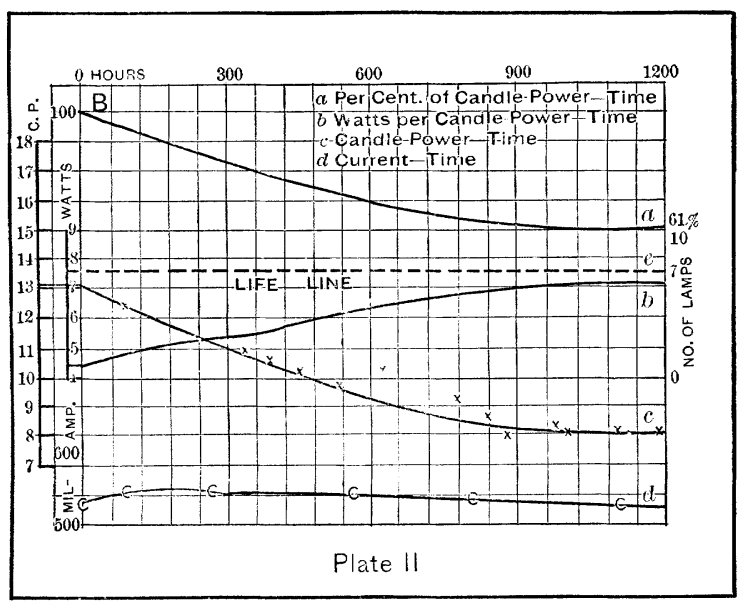

our taking readings as often as we would like to have done, and prevented also the examination of a number of points of interest which developed as the test progressed. For the same reason we

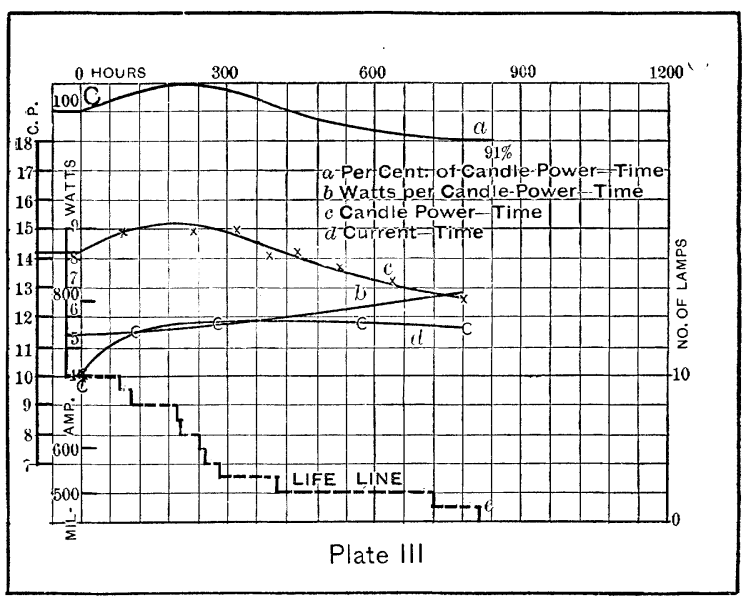

are unable to include the data and curves for the individual lamps.

Thirty-one lamps in all were broken, distributed as follows: All of the C's (10), 2 D's, 8 E's, 2 K's, 4 L's, 1 M and 2 N's. All 
the lamps of $A, B, F, G$ and $O$ makes survived, the $O$ 's for 1,013 hours, the others for 1,200. The average life of the C's was 386 hours.

Plate XIV. gives two sets of curves. One set gives the curve of general average of percentage of initial candle power with respect to time, derived from the averages of the several makes, and beside it, the curve of the make which showed highest percentage throughout, marked min. drop. make $M$, and also the curve showing lowest percentage, marked max. drop, make L. The other set shows the general average of watts per candle power, and also the curves of the two makes showing the maximum (make $\mathrm{N}$ ) and minimum (make $\mathrm{M}$ ).

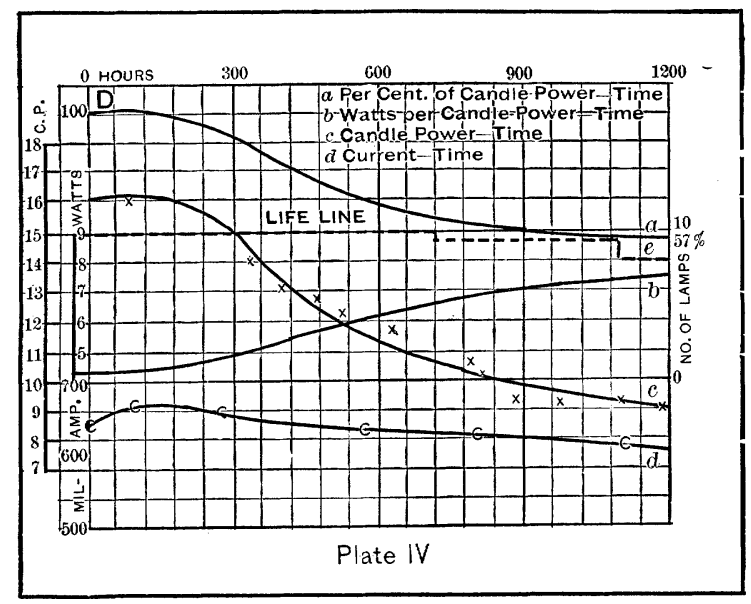

Examining the results first for candle power, we find the value 14.5 as the average of all the lamps tested at the time the current was first turned on them. Of the 13 separate lots, six only show an initial candle power of 16 candles (neglecting tenths), though one make which started at below 15 rises above 16 within the first 100 hours. The lowest initial candle power is found for make M. Makes $\mathrm{G}, \mathrm{K}$ and $\mathrm{O}$ start at 17 candle, the highest figure reached at the start.

Looking at the curve which gives the average percentage of initial candle power, Plate XIV., we find that the lamps on the average grow dim at a steady rate, falling off to 90 per cent. in about 200 hours, to 68 per cent. in 600 hours, and end at 1,200 hours with a little less than 55 per cent. Deferring the consid- 
eration of the $\mathrm{C}$ lamps, the M lamps sustain their power best, losing only about six per cent. in the first 300 hours, and ending a little under 70 per cent. of their initial candle power. The L

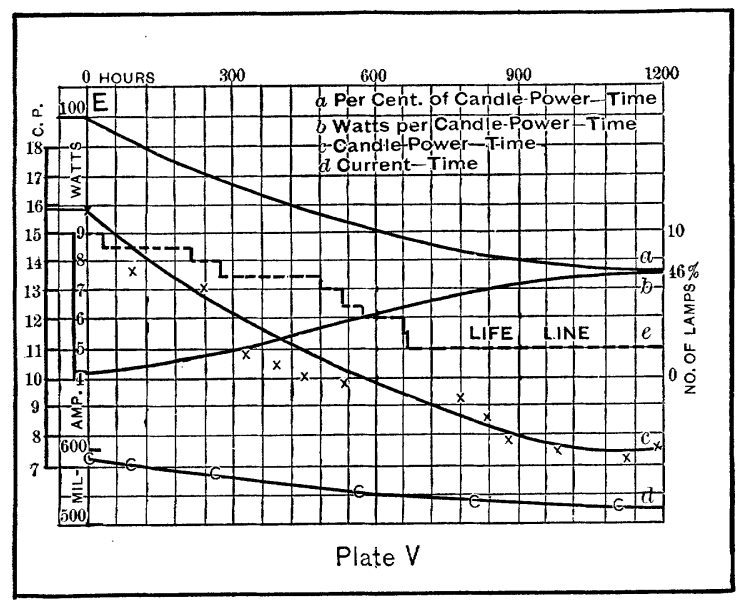

lamps drop rapidly on the start, losing 30 per cent. in the first 300 hours and ending at 54 per cent. The E's and the O's drop to 47 per cent. at the close, but sustain themselves better than the L's in the earlier part of the run.

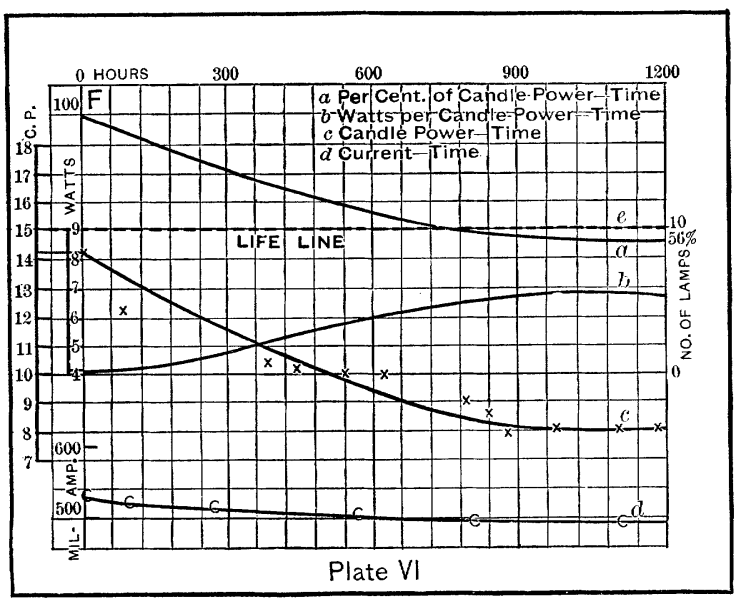

With respect to efficiency, using the term in its ordinary signification, as measured by watts per candle power (though in this sense the reciprocal is the proper measure), Plate XIV. shows an 
average initial value of 4.2 , rising to 5.0 at 300 hours, 5.9 at 600 hours, 6.8 at 900 hours, and 7.0 at the end. The M lamps again have the best place, starting high but ending low, at six watts per candle power.

But what shall we say of the results as bearing on the question of the life of the lamp? The answer depends on what we shall define the life of a lamp to be.

Is a lamp alive as long as current will go through it? Some advertisers think so, and they seem to have support in their opinion, for some of their patrons have sent them, with complimentary remarks, lamps through which current is said to have passed for 6,000 hours or more. Adopting this view, our test

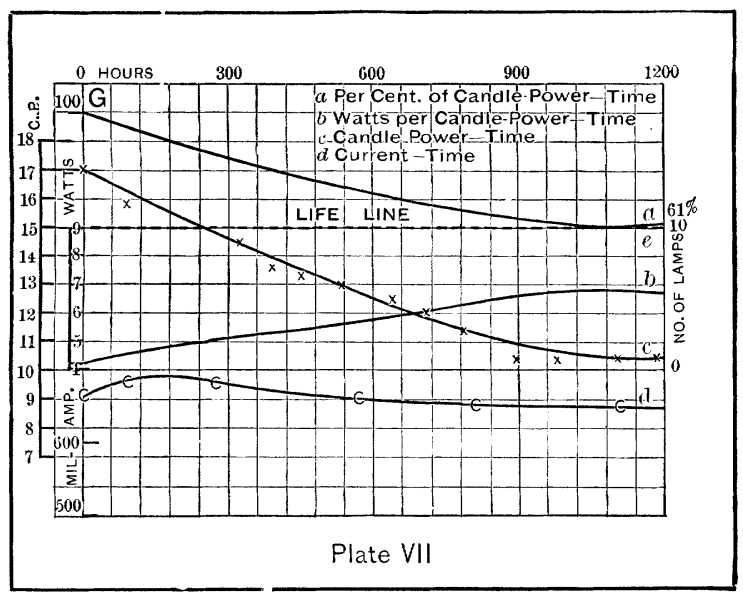

shows 96 out of 127 lamps decidedly alive at the end of an average of 1,120 hours, and the leveling of the average curves of Plate XIV. promises a considerable extension of their existence; 31 only have proven their mortality, and several of them lived to a good old age. The C's, poor things, all died young.

If we set the time of decease at the time when the lamp gives 50 per cent. of its initial candle power, as some claim, the lamps tested have passed 1,000 hours on the average, and certain makes have passed 1,200 . If life be defined still with reference to percentage of initial candle power, but the limit be placed at 75 per cent., some individuals are still alive, but on the average, all died at 450 hours; 80 per cent. as limit cuts them off at 330 hours, and 90 per cent. at 180 . 
But there is yet another way of defining the life of a lamp. The one who ultimately pays for the lamp is the one whose premises are lighted by it, and the thing he is supposed to pay for is

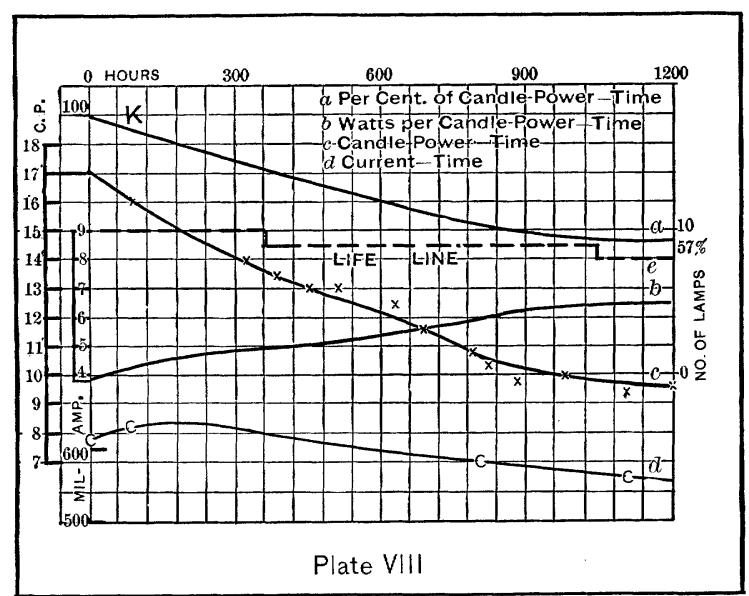

light. For him, the lamp is dead when it ceases to give a certain candle power, without reference to what its candle power was when it was new. His premises, let us suppose, are properly lighted by a certain number of new lamps which actually give

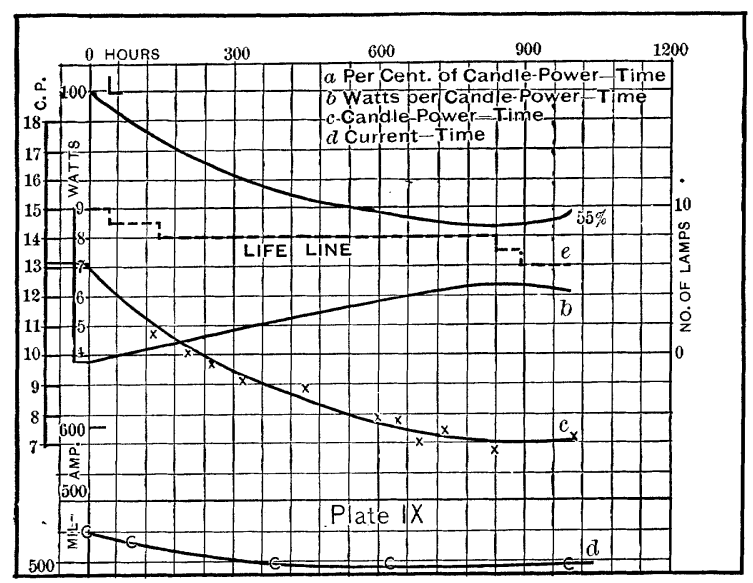

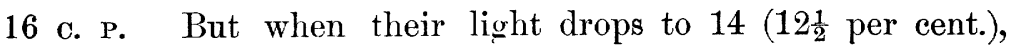
he is no longer satisfied (and he ought not to be). For him the average lamp lasts about 240 hours. But if he is at liberty 
to choose the make of the lamp, without reference to its efficiency, he will probably call for lamps of the G make, and get 400 hours service from them. If, however, he can induce the maker of the $\mathrm{M}$ lamp to make a lamp giving $16 \mathrm{c}$. P. when new, and having the same characteristics as those we tested, he will choose M's, and get 500 hours life. And that is the best that can be done for him, so far as this test shows. He would not have B's, L's or M's, as at present made at all, because they do not give 14 c. P. when new, and if the station manager put in F's or N's he would order them out in less than a week. The state of things revealed by this test, as to the actual candle power of new lamps, is certainly not what it ought to be.

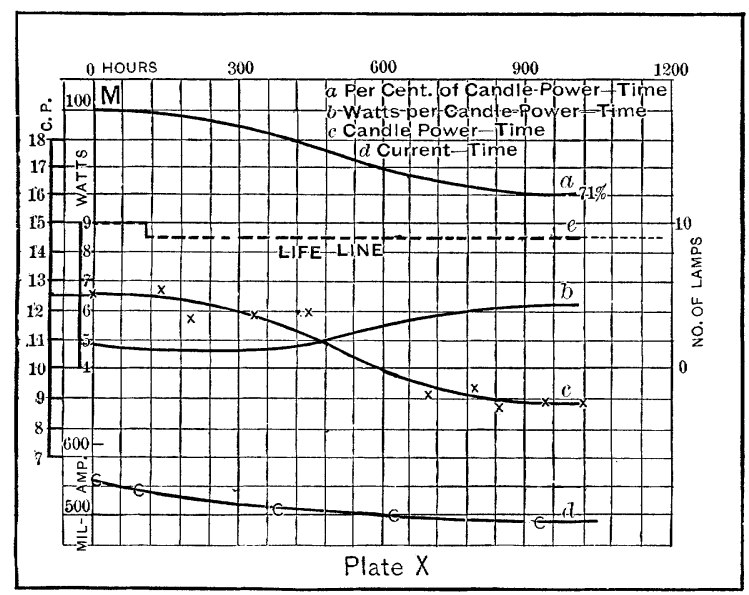

At the conclusion of the life test we dismounted all the lamps and placed them on a large table covered with clean drawing paper and uniformly lighted. The several lots were carefully examined with reference to blackening, the lot which was blackened the most being graded 100, and the other lots graded as closely as we could judge by comparison with the blackest lot and with one another. The grades are as follows: $10,12 \frac{1}{2}, 25,28,30,32,35,42,45,50,75$ and 100 per cent. of the blackening of the blackest lot. When the sorting and grading was satisfactorily completed, and the letters on the lamp bases examined, it was remarked that the two lots which were least blackened were of the makes which are advertised as exhausted 
by mechanical pumps. That they should both"be so much alike in blackening, and both only one-half as much blackened as the least blackened of the mercurially exhausted lamps, is, to say the

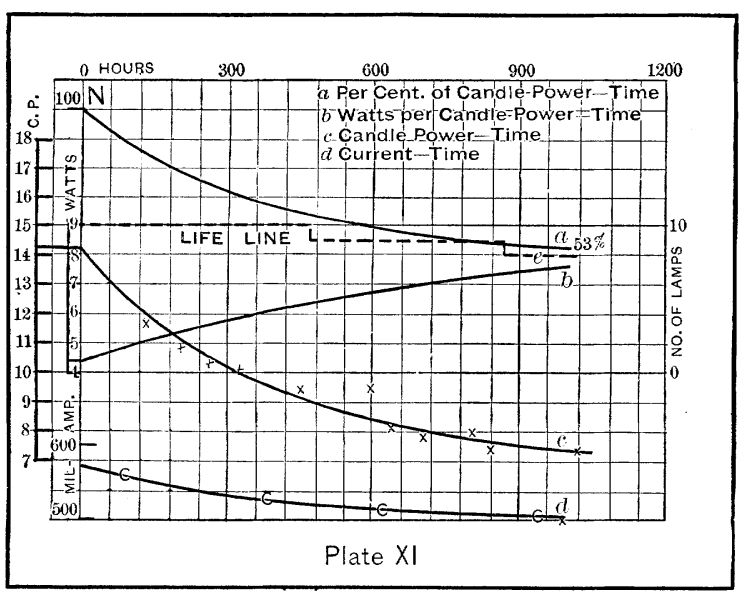

least, worthy of notice. It is, of course, not established that the observed freedom from blackening is due to the absence of mercury vapor in the lamps, as the makers claim, but if investigation

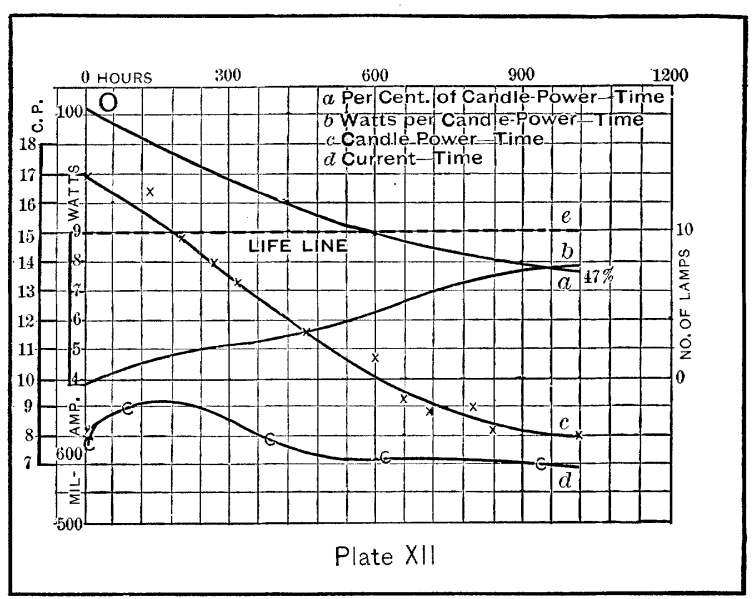

should establish the claim the mercury pump will probably become once more a laboratory instrument. [The lot of lamps graded 10 per cent., and the lot graded 100 per cent., were 
mounted together on cardboard and exhibited.] As the giving of the letters designating the several lots of lamps, with the percentages of blackening, would, after the above statements, serve to identify the makers in the preceding tables and curves, the letters are omitted.

With regard to the performance of individual lamps of each lot, we found in some makes greater uniformity than in others, indicating either greater uniformity in manufacture or greater care in sorting the finished lamps on the part of some makers. The A lamps were among the best in this respect, and the C's and F's among the poorest. [Curves showing the individual performances of the lamps of the three lots named were here shown and discussed.]

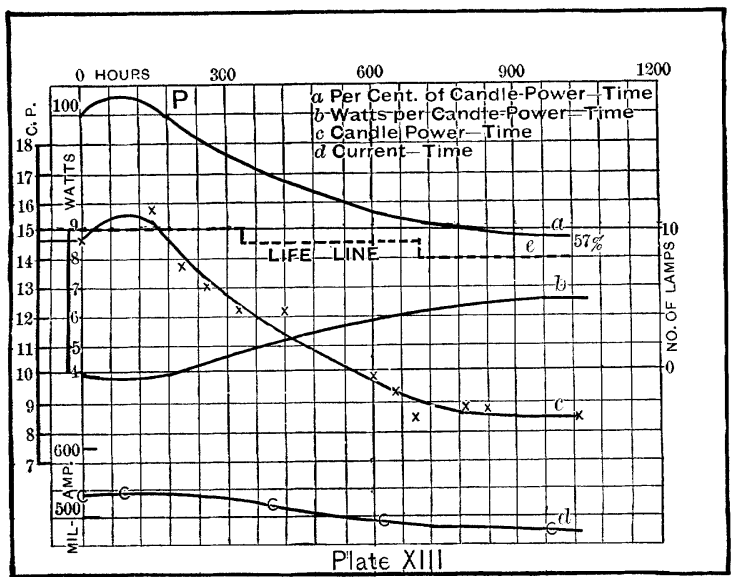

So far as the lamps tested may be considered to fairly represent it, we draw from the test the following conclusions concerning the average 16 c. P., 110 volt, incandescent lamp :

First. The mean horizontal candle power of the lamp as defined, is only 14.5 when new instead of 16 as labeled.

Second. The candle power of the lamp diminishes at a fairly uniform rate as it is burned, the rate of decrease being roughly 10 per cent. of the initial candle power for each 200 hours burned.

Third. The lamp makers' claim, that the lamp will burn for 600 hours before breaking, is more than established, 96 out of 127 lamps being unbroken at the end of over 1,100 hours.

Fourth. Defining the life of a lamp to be the number of hours 
it will burn before it will fall from 16 c. P. to 14 , we find the life of lamps in all respects like those tested, but so made as to give an initial candle power of 16 , is 240 hours.

Fifth. The initial efficiency of the lamp is 4.2 watts per candle power. At 600 hours it is 5.9 watts and 1,200 hours 7 watts. The average efficiency during the first 600 hours is 5.04 watts.

Sixth. There is considerable difference in the rating of lamps by different makers, who nominally furnish the same article, the average initial candle powers of the several lots ranging from 12.5 to 17.0. There is also considerable difference in the unformity of the product of different makers.

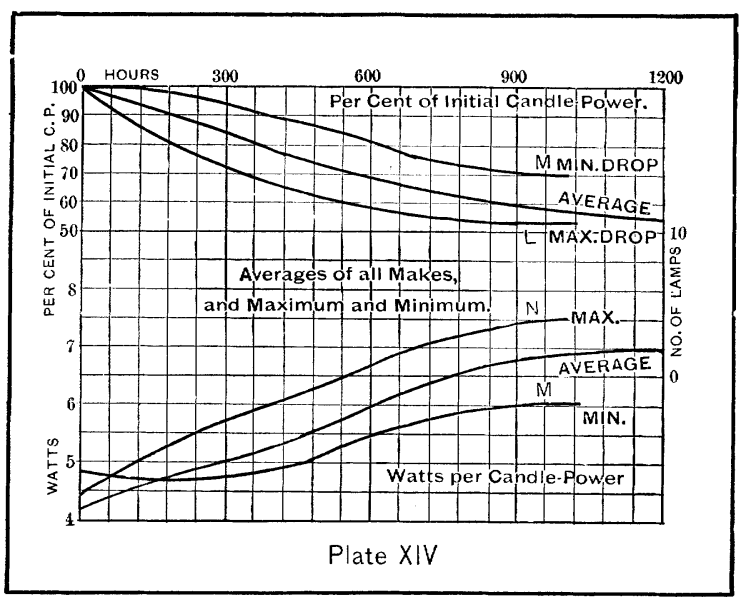

The above conclusions properly complete this paper, so far as the purpose for which the test was undertaken is concerned. Some interesting points in the relative performances of different lamps may perhaps be alluded to in addition, since they cannot affect the makers.

Referring to Table V., lamps A, K, L and $\mathrm{O}$ have the same initial efficiency ( 3.9 watts per candle power), and for the first 700 hours $\mathrm{A}$ and $\mathrm{L}$ keep together, rising to 6.1 watts. $\mathrm{K}$ does better, rising only to 5.6 watts per candle power, while $O$ rises to 6.9 watts. Referring to Table IV., there is greater difference among the makes named, the K's at 700 hours giving 67 per cent. of their initial candle power, while the A's give 61 per cent. and the L's and O's only $5 \check{5}$ per cent. Of the four makes therefore the K's are best, since they maintain their candle power better and have the highest average efficiency. The differences, however, 
are so small as to make noteworthy the similarity between lamps of the same class, coming from different factories, as in this case. Comparing the F's with the G's in the same table, the F's have a slight advantage in efficiency on the start, but they come together in 500 hours. The G's, however, have such an advantage in the way they hold up in brilliancy as to balance the slight difference in efficiency and make them the better lamp.

The most interesting result, however, arises from a comparison of the lamps L and M. The L's have the highest initial efticiency (3.8), and the M's the lowest (4.8), excluding, of course, the C's, which can not be classed with good lamps, but after 250 hours burning the efficiencies are the same (4.75). At the start the L's are furnishing light at the least cost, but after 250 hours the M's have the advantage in this respect. If we suppose both makes to be used for 700 hours, the average efficiency is the same for both. But at this time the M's are giving 75 per cent. of their initial candle power, while the 'L's are giving only 55 per cent. For the consumer the M lamp is the better of the two, since the lighting of premises will be more uniform throughout the 700 hours of use supposed, and the cost of current for a given aggregate of candle power hours is no greater than with the L's. If the time of use of the lamps be, say, 400 hours, the choice is not so evident, and will depend on whether the slight difference in cost (watt hours) is of greater or less importance, than constancy of candle power of the lamps.

A rongh graphic comparison between the several makes of lamps may be made by considering the areas between the curves $c$ and $a$ of the several plates. The curve $a$ is evidently parallel (raised three divisions) to the curve $c$, which would have been found if the initial candle power of each lamp had been 16 as labeled, other things being unchanged. The more nearly horizontal $a$ and $b$ are, and the lower $b$ is, the better the lamp. As drawn, the curves can only give qualitative results by such comparison, but if the scale to which the $b$ curves are drawn were properly chosen, the area comparison might give more accurate conclusions as to the relative merit of the several makes. It is clear that the form of the area between the $a$ and $b$ curves in Plate X. is nearer the ideal than any other, and that Plate XI. is poor. We are inclined to the belief that facts such as those alluded to in the comparison of the lamps L and M may lead to a modification of the views commonly expressed as to high and low efficiency lamps. 


\section{Discussion. ${ }^{1}$}

The Chairman [Vice-President Hering.] We can be congratulated on having such a paper as this one, at our meetings. It is papers of this kind that are read with great interest by electrical engineers all over the country and bring the Institute such a good reputation. Any one who has ever attempted tests of this sort will know how very tedious it is to carry on such a long set of observations. There are a number of gentlemen in the room who have worked in this same field from whom we would be very glad to hear.

PROFEsSor RoBerts:-With reference to the comparative testing of lamps--there are three methods:

1st. Running lamps at the voltage marked and measuring the c. P. and current during life, and plotting the curves in the manner Prof. Thomas has done. 2d. Running all lamps at the voltage at which they originally gave the c. P. marked, and in other respects proceeding as in the first case. 3d. Operating all lamps at the same efficiency. It is impossible to make comparisons when the test follows the first plan. Although the paper is of interest and valuable, it does not, to any extent, give comparative facts. The same objections hold good, for the must part, to the second plan. The proper method is to obtain lamps of the same efficiensy; and if to be of the greatest value, as near as inay be of the efficiency desired to use; and start them on the same basis. All large manu facturers of lamps make any efficiency desired; we have orders for $16 \mathrm{c}$. P. lamps between the limits of 50 watts and 75 wat ts--our standard being 55 watts.

Prof. Thomas states lamps purchased in the open market vary in c. P. I desire to mention the lack of knowledge of what is wanted on the part of the customer. In all probability the lamp will not be used within 4 per cent. of the voltage ordered for the greater portion, probably all of its life, and such a departure in the matter of voltage will make more difference in c. P. than is likely to exist in lamps sent out by the better manufacturers, although not by all. Probably 50 volt lamps are going to burn at 54 volts and 110 's at 114 to 116 volts.

With reference to the life of the lamp and to blackening. It is true of some stations that when the lamp becomes blackened it is considered dead and removed, but in many stations the following method is pursued:- The manager receives a complaint that some good customer has not light enough, and he instructs his superintendent to " raise the voltage a little." The next day he visits the customer and all are happy. When the end of the month comes and the "lamp renewals" report is shown him he

1 This paper, as originally presented, was discussed at length by Mr. J. W. Howell, and has since been revised by the author. In view of the changes made therein, Mr. Howell's remarks, as well as those of the author in reply have been withdrawn.-EDitor. 
immediately complains to the lamp manufacturer. I recently had occasion to inspect a large isolated plant. The office had the lowest voltage (tne distribution was very bad, owing to additions of lights since original installation and without increase of wires), the consequence was that the lamps had lasted for thousands of hours, but were very black and were giving about four c. P. In the warerooms, where plows and other bulky articles are stored, the lamps gave about 25 c. P., and had a short life. I advised the renewing of all lamps in the office the first of each month (statement time) and taking the old lamps for the warehouse.

The paper does not touch upon the fact, that the source of most of the complaints about lamps is the lack of appreciation of the effect of variation of voltage on life. I have been a manager and superintendent of electric light stations as well as a manufacturer of lamps and, therefore, have had experience on both sides. There are many places which we have investigated where practically, the above effect was not appreciated in the least. Many do not know what voltage they actually have at the lamp even at one time, and "suppose all the lamps are at the same voltage at all times as they take care it should be so at the station." As it is impossible to have actually constant voltage, and as one can not tell a customer that he does not know what he is talking about, it is only by saying, "of course, as you know," and "you know that," etc., that, in the course of time, he does know it. There is no "manufacturers standpoint." There is no reputable manufacturer but desires his customer to know all possible about the goods sold. The more the customer knows the better for the manufacturer. It is by personal missionary work and by the publication of such papers as the one we have just heard that the conditions necessary for the most satisfactory use of the lamp can be made known to the average purchaser of incandescent lamps. 